\title{
In vitro Evaluation of Linezolid and Doripenem Clearance with Different Hemofilters
}

\author{
Toshihisa Hiraiwa $^{a}$ Kazuhiro Moriyama ${ }^{b}$ Kana Matsumoto ${ }^{c}$
}

Yasuyo Shimomura $^{\text {a }}$ Yu Kato $^{a}$ Chizuru Yamashita $^{a}$ Yoshitaka Hara $^{\text {a }}$

Takahiro Kawaji $^{\text {a }}$ Yasuyoshi Kurimoto ${ }^{a}$ Tomoyuki Nakamura ${ }^{a}$

Naohide Kuriyama $^{a}$ Junpei Shibata ${ }^{a}$ Hidefumi Komura $^{a}$ Kunihiko Morita ${ }^{c}$

Osamu Nishida ${ }^{a}$

a Department of Anesthesiology and Clinical Care Medicine, Fujita Health University School of Medicine, Toyoake, Japan; 'baboratory for Immune Response and Regulatory Medicine, Fujita Health University School of Medicine, Toyoake, Japan; 'Department of Clinical Pharmaceutics, Faculty of Pharmaceutical Sciences, Doshisha Women's College of Liberal Arts, Kyotanabe, Japan

\section{Keywords}

Experimental model · Adsorption · Hemofilter · Linezolid · Doripenem

\begin{abstract}
Introduction: Renal replacement therapy (RRT) is widely used in the treatment of septic acute kidney injury. However, little is known about how the adsorption properties of hemofilters used in RRT affect antibiotic concentration. Because a cytokine-adsorption membrane is frequently used in RRT, it is important to determine the antibiotic adsorption capacity of this membrane. Objective: The present study aimed to investigate the antibiotic adsorption capacity of different hemofilter membranes by in vitro experiments using 2 antibacterial agents (linezolid and doripenem). Methods: We performed experimental hemofiltration in vitro using polyacrylonitrile (AN69ST), polymethylmethacrylate (PMMA), and polysulfone (PS) hemofilters for 1,440 min. The
\end{abstract}

test solution was a $1,000-\mathrm{mL}$ substitution fluid containing 30 $\mu \mathrm{g} / \mathrm{mL}$ linezolid and $120 \mu \mathrm{g} / \mathrm{mL}$ doripenem. We measured drug concentrations at the inlet, outlet, and filtrate ports of the hemofilters for 1,440 min and calculated the sieving coefficient (SC) and adsorption rate (Ra) of the drugs onto the hemofilters. Results: The amount of linezolid adsorbed onto AN69ST, PMMA, and PS membranes was decreased relative to that in the control group at $15 \mathrm{~min}(p<0.05)$. However, no SC for linezolid was obtained thereafter. The Ra of linezolid onto AN69ST, PMMA, and PS membranes was higher than that in the control group $(p<0.05)$. In contrast, no significant differences were observed in the concentrations and Ra values of doripenem adsorbed onto AN69ST, PMMA, and PS membranes compared with those in the control group. Conclusions: Doripenem was not adsorbed onto PMMA, PS, and AN69ST membranes. Linezolid was adsorbed onto PMMA, PS, and AN69ST membranes, but only temporarily, and this did not affect drug bioavailability.

(C) 2020 The Author(s)

Published by S. Karger AG, Basel

\begin{tabular}{ll}
\hline KARGER & $\begin{array}{l}\text { (c) } 2020 \text { The Author(s) } \\
\text { Published by S. Karger AG, Basel }\end{array}$ \\
karger@karger.com & This article is licensed under the Creative Commons Attribution- \\
www.karger.com/bpu & NonCommercial-NoDerivatives 4.0 International License (CC BY- \\
NC-ND) (http://www.karger.com/Services/OpenAccessLicense). \\
Usage and distribution for commercial purposes as well as any dis- \\
tribution of modified material requires written permission.
\end{tabular}

Kazuhiro Moriyama

Laboratory for Immune Response and Regulatory Medicine Fujita Health University School of Medicine

1-98 Dengakubo, Kutsukake-cho, Toyoake, Aichi 470-1192 (Japan)

E-Mail morimori@fujita-hu.ac.jp 


\section{Introduction}

Sepsis is the primary cause of acute kidney injury (AKI) in intensive care units (ICUs), accounting for half of all AKI cases [1,2]. Management of septic AKI is based on early resuscitation and timely administration of appropriate antibiotics. Although renal replacement therapy (RRT) offers hemodynamic and metabolic stability and fluid balance, there are increasing concerns about its impact on antimicrobial treatment. Linezolid and doripenem are antibiotics that are commonly used against resistant bacteria in ICUs [3, 4]. Linezolid is efficacious against Gram-positive bacteria including methicillin-resistant Staphylococcus aureus or vancomycin-resistant enterococci, and therefore frequently used in ICU patients [3, 5]. The most common linezolid-dosing regimen is 300 $\mathrm{mL}$ infusion bag $(600 \mathrm{mg})$ every $12 \mathrm{~h}$. Linezolid is often administered, in combination with RRT because of the daily infusion load of $600 \mathrm{~mL}$, but its reported side effect include thrombocytopenia during renal dysfunction has been reported. Although Carbapenems are not first line of antibiotics in ICUs, they are frequently used in critically ill patients. Especially in severe sepsis and septic shock are major causes of morbidity and mortality in the ICUs, applicable international guidelines early recommend the early use of carbapenems as empirical therapy [5]. Owing to their hydrophilicity, they are readily removed by hemofilters during RRT for septic AKI $[6,7]$. Appropriate antibiotic therapy during RRT is critical because it affects both the patients' prognosis and the emergence of resistant bacteria. Antibiotic dosing in RRT is complex, and current approaches are imprecise. Antibiotic elimination is influenced by patient and drug factors and various aspects of RRT technique, such as filtration and dialysis [ 8,9$]$. However, little is known about how the adsorption properties of hemofilters used in RRT affect antibiotic concentrations in patients.

In Japan, cytokine-adsorbing hemofilters are frequently used in RRT. Adsorption of antibiotics onto these filters is an important consideration because it can affect treatment. In this study, we investigated potential changes in linezolid and doripenem dosage caused by their adsorption onto hemofilters by performing in vitro experiments using 3 types of hemofilters.

\section{Materials and Methods}

\section{Preparation of Solution}

The test solution was prepared by dissolving $35 \mathrm{~g}$ of fetal bovine serum (FBS; MW 66.5 kDa; Wako Pure Chemical, Osaka, Japan) in

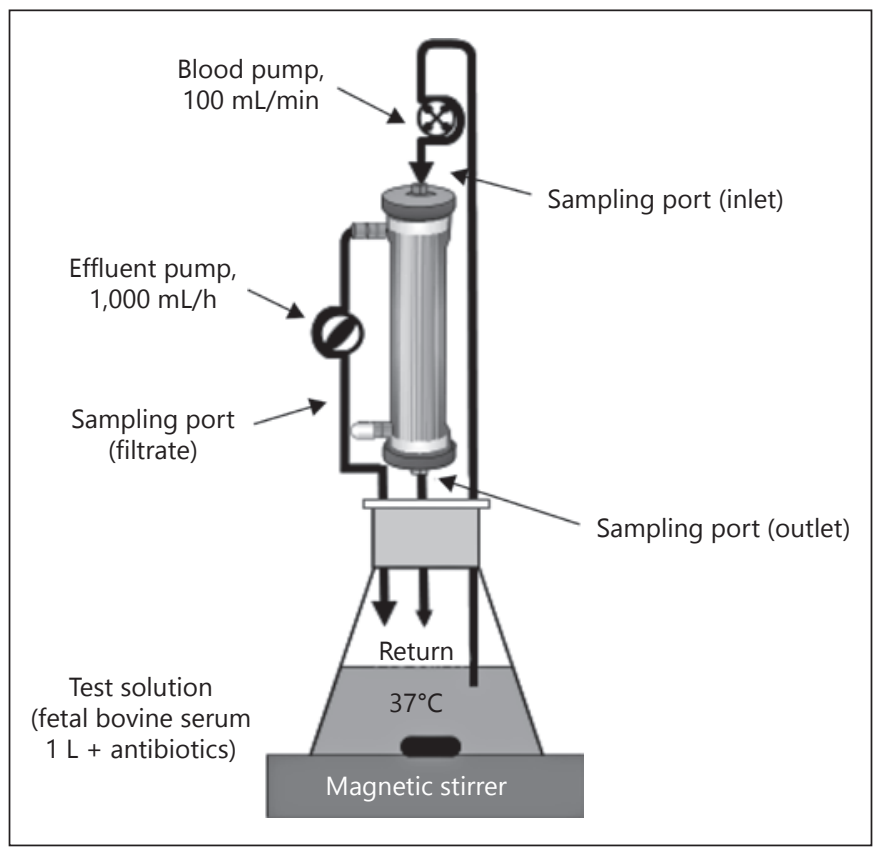

Fig. 1. Schematic representation of closed-circuit circulation. The parameters of the experimental circuit $(\mathrm{CBi}, \mathrm{CBo}$, and $\mathrm{CF}$ ) were measured as indicated according to the procedure used in clinical application.

1,000 mL of bicarbonate Ringer's solution (BICANATE Injection ${ }^{\circledR}$; Otsuka Pharmaceutical Factory, Tokushima, Japan). We adopted a closed circulation circuit and prepared linezolid and doripenem as the target drugs, and the concentrations were adjusted to 30 and 120 $\mu \mathrm{g} / \mathrm{mL}$, respectively, by dissolving in 1,000 mL FBS.

\section{Hemofiltration Procedure}

Filtration of the test solution was initiated at a temperature of $37^{\circ} \mathrm{C}$ and using a magnetic stirrer to ensure uniform drug concentration throughout the circuit. The test solution was pumped from the solution reservoir to the hemofilter at a solution flow rate of 100 $\mathrm{mL} / \mathrm{min}$ and a filtrate flow rate of $1,000 \mathrm{~mL} / \mathrm{h}$. Experimental hemofiltration was conducted for 1,440 min using a fully automated instrument (TR525 ${ }^{\circledR}$; Toray industries, Tokyo, Japan; Fig. 1).

We used the following 3 types of hemofilters - each with a surface area of $1.0 \mathrm{~m}^{2}$ (Table 1) - that are used in clinical practice: polyacrylonitrile (AN69ST) hemofilter (AN69ST; Baxter Limited, Tokyo, Japan), polymethylmethacrylate (PMMA) hemofilter (Hemofeel ${ }^{\circledR} \mathrm{CH}-1.0 \mathrm{~N}$; Toray Industries Co., Ltd., Tokyo, Japan), and polysulfone (PS) hemofilter (Excel Flow ${ }^{\circledR}$; Asahi Kasei Medical Co., Ltd., Tokyo, Japan).

In the control group, ultrafiltration was performed using only the circuit without any membrane. The filter and an extracorporeal circuit were primed with $1,000 \mathrm{~mL}$ of heparinized saline solution (5,000 IU).

\section{Sampling Method and Evaluation Parameters}

Circulation was carried out for 3 min to maintain a constant antimicrobial concentration in the reservoir and FBS circuit. The time after circulation for $3 \mathrm{~min}$ was set as time 0. Experimental 
Table 1. Characteristics of the different hemofilters tested in this study

\begin{tabular}{|c|c|c|c|c|c|c|}
\hline & Material & Structure & $\begin{array}{l}\text { Surface } \\
\text { area, } \mathrm{m}^{2}\end{array}$ & $\begin{array}{l}\text { SC alb, } \\
\%\end{array}$ & $\begin{array}{l}\text { Inner } \\
\text { diameter, } \mu \mathrm{m}\end{array}$ & $\begin{array}{l}\text { Wall } \\
\text { thickness, } \mu \mathrm{m}\end{array}$ \\
\hline AN69ST & AN69ST (surface treated) & Symmetric & 1.05 & $<0.1$ & 210 & 42 \\
\hline $\mathrm{CH}-1.0 \mathrm{~N}$ & PMMA & Symmetric & 1.0 & 0.7 & 200 & 30 \\
\hline Excel flow & PS & Asymmetric & 1.0 & $<0.1$ & 225 & 45 \\
\hline
\end{tabular}

SC, sieving coefficient; AN69ST, polyacrylonitrile; PMMA, polymethylmethacrylate; PS, polysulfone.

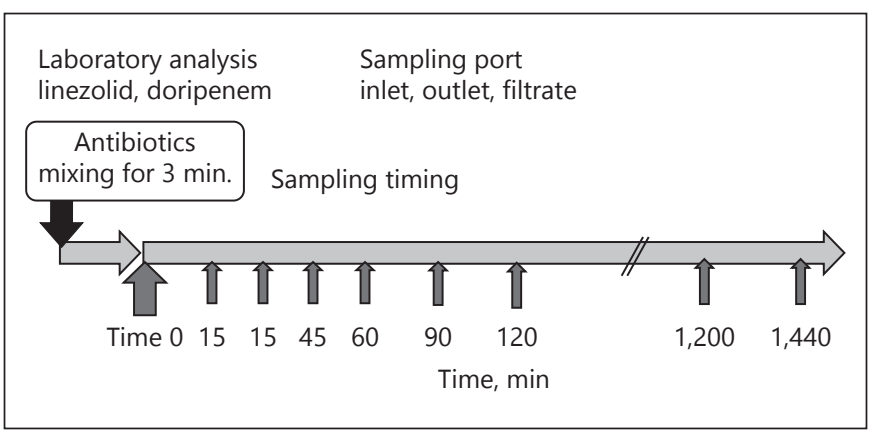

Fig. 2. Sampling timing for laboratory analysis. The concentrations of linezolid and doripenem from the inlet, outlet, and filtrate ports at different sampling points are shown. The circuit for $3 \mathrm{~min}$ and filled with solution and starting the experiment.

hemofiltration was performed for $1,440 \mathrm{~min}$ at $37^{\circ} \mathrm{C}$, and samples for analysis of antibiotic concentration were collected from both the inlet and outlet of the hemofilter and from the filtrate port at different time points (Fig. 2). Linezolid and doripenem concentrations in the samples obtained from the inlet, outlet, and filtrate ports in the control group and in the AN69ST, PMMA, and PS membrane groups were measured by high-performance liquid chromatography (HPLC).

Plasma linezolid level was quantified by HPLC as previously reported [10], with some modifications. The sample was deproteinized by adding acetonitrile, vortexed for $30 \mathrm{~s}$, and centrifuged at 3,000 rpm for $10 \mathrm{~min}$. The supernatant $(20 \mu \mathrm{L})$ was analyzed on an HPLC system consisting of LC-20AT solvent delivery pumps, and an SPD-10Avp detector (Shimadzu, Kyoto, Japan). The analytes were separated on a InertSustain ${ }^{\circledR} \mathrm{C} 18$ column (4.6 $\mathrm{mm}$, inner diameter $=150 \mathrm{~mm}$; GL Sciences, Tokyo, Japan). The mobile phase consisted of $1 \%$ ortho-phosphoric acid, $30 \%$ methanol, and $2 \mathrm{~g} / \mathrm{L}$ heptane sulfonic acid adjusted to $\mathrm{pH}$ 5.0. The flow rate was $1.0 \mathrm{~mL} / \mathrm{min}$, and linezolid was detected at $254 \mathrm{~nm}$.

The retention time of linezolid was $10.0 \mathrm{~min}$, and the lower limit of detection was $0.1 \mu \mathrm{g} / \mathrm{mL}$. The intra-and inter-day variations of linezolid concentration measurements were $<5 \%$ in this assay.

Doripenem concentration was measured with the meropenem assay as previously reported [11], with some modification. After deproteinizing $100 \mu \mathrm{L}$ of the sample by adding $300 \mu \mathrm{L}$ of methanol, the sample was centrifuged at 3,000 rpm for $10 \mathrm{~min}$, and $30 \mu \mathrm{L}$ of the supernatant was injected into an HPLC system consisting of a liquid

Linezolid and Doripenem Adsorption onto Different Hemofilters transport unit (LC-20AB; Shimadzu) and a spectrophotometer (SPD-20A; Shimadzu). The mobile phase was a mixture of PIC-A reagent/methanol (82:18), the flow rate was $1.0 \mathrm{~mL} / \mathrm{min}$, the detection wavelength was $300 \mathrm{~nm}$, and a HYPERSIL, ODS-5 column was used $(4.6 \mathrm{~mm}$, inner diameter $=250 \mathrm{~mm}$; Chemco Scientific, Osaka, Japan). The retention time of doripenem was $7.7 \mathrm{~min}$, and the lower limit of detection was $0.1 \mu \mathrm{g} / \mathrm{mL}$. The intra- and inter-day variations in doripenem concentration measured with this assay were $<5 \%$.

Validation of these measurement methods was performed based on the Guideline on Bioanalytical Method Validation in Pharmaceutical Development [12].

Sieving coefficient (SC) was calculated using the following equation:

$$
\mathrm{SC}=2 \mathrm{CF} / \mathrm{CBi}+\mathrm{CBo}
$$

where $\mathrm{CBi}, \mathrm{CBo}$, and $\mathrm{CF}$ are the linezolid and doripenem concentrations in the test solution at the inlet, outlet, and filtrate ports, respectively, of the hemofilter.

The amount of drug adsorbed onto the membranes was assayed at $0,15,30,45,60,90,120,360$, and $1,440 \mathrm{~min}$. Adsorption rate ( $\mathrm{Ra})$ was calculated using the following equation:

$\mathrm{Ra}=([$ time 0 concentration - time 1,440 min concentration $] /$ time 0 concentration $) \times 100 \%$

Adsorption of antibacterial agents onto hemofilters was evaluated based on Ra value.

\section{Statistical Analysis}

The results are expressed as mean values \pm SD. Differences in adsorption of antibiotics onto AN69ST, PMMA, and PS membranes compared to that in the control group ( $n=4$ per group) were evaluated by one-way analysis of variance using the JMP software for SAS (SAS Institute, Cary, NC, USA). $p<0.05$ was considered statistically significant.

\section{Results}

\section{Concentration, SC, and Ra of Linezolid}

Time Course of Linezolid Concentration

The amount of linezolid adsorbed onto the $3 \mathrm{mem}$ branes decreased at $15 \mathrm{~min}$ and remained constant until $1,440 \mathrm{~min}$. 
Table 2. Adsorption rate of antibiotics onto AN69ST, PMMA, and PS membranes

\begin{tabular}{llllrl}
\hline & \multicolumn{1}{l}{ Ra } & & & \\
\cline { 2 - 6 } & AN69ST & PMMA & PS & Control & $p$ value \\
\hline Linezolid, \% & $11.4 \pm 1.9$ & $22.0 \pm 1.1$ & $14.5 \pm 3.7$ & $1.7 \pm 1.2$ & $<0.01^{*}$ \\
Doripenem, \% & $24.0 \pm 2.5$ & $25.5 \pm 1.8$ & $27.7 \pm 2.5$ & $23.5 \pm 2.5$ & 0.06 \\
\hline
\end{tabular}

$* p<0.05$ vs. the control group (analysis of variance).

Adsorption rates of linezolid $(30 \mu \mathrm{g} / \mathrm{mL})$ and doripenem $(120 \mu \mathrm{g} / \mathrm{mL})$ are shown as mean \pm SD of 4 experiments.

Ra, adsorption rate; AN69ST, polyacrylonitrile; PMMA, polymethylmethacrylate; PS, polysulfone.

The concentration of linezolid adsorbed onto the membranes decreased significantly from 0 to $15 \mathrm{~min}$ relative to that in the control group (AN69ST: $29.0 \pm$ 0.2 to $27.9 \pm 0.6 \mu \mathrm{g} / \mathrm{mL}$; PMMA: $28.8 \pm 0.6$ to $23.6 \pm$ $1.0 \mu \mathrm{g} / \mathrm{mL}$; PS: $27.1 \pm 0.5$ to $26.6 \pm 0.8$; control: $29.4 \pm$ 0.7 to $29.1 \pm 1.0 \mu \mathrm{g} / \mathrm{mL} ; p<0.05)$. No significant changes were observed in the linezolid concentrations absorbed among the 3 membranes after $15 \mathrm{~min}$ (Fig. 3).

\section{SC of Linezolid}

The linezolid SC of AN69ST, PMMA, and PS membranes was $0.85 \pm 0.01,0.86 \pm 0.02$, and $0.85 \pm 0.03$, respectively, with no significant differences observed at 1,440 min among the 3 types of membrane.

Ra of Linezolid

The Ra values for linezolid adsorption onto AN69ST, PMMA, and PS membranes were $6.6 \pm 2.2,17.7 \pm 1.5$, and $10.3 \pm 1.8 \%$, respectively; these values were higher than the Ra for linezolid in the control group (1.20 $\pm 1.5 \%$; $p<$ 0.05; Table 2).

\section{Concentration, SC, and Ra of Doripenem}

Time Course of Doripenem Concentration

The concentration of doripenem adsorbed onto the membranes decreased from 0 to 1,440 min relative to that in the control group (AN69ST: $94.5 \pm 3.1$ to $72.0 \pm$ $2.7 \mu \mathrm{g} / \mathrm{mL}$; PMMA: $91.7 \pm 1.7$ to $69.8 \pm 2.0 \mu \mathrm{g} / \mathrm{mL}$; PS: $94.2 \pm 2.9$ to $70.9 \pm 2.8 \mu \mathrm{g} / \mathrm{mL}$; control: $92.5 \pm 3.8$ to $72.0 \pm 2.5 \mu \mathrm{g} / \mathrm{mL}$ ). None of these decreases were statistically significant compared with the control group (Fig. 4).

\section{SC of Doripenem}

The doripenem SC of AN69ST, PMMA, and PS membranes were $0.90 \pm 0.09,0.92 \pm 0.09$ and $0.95 \pm 0.05$, re-

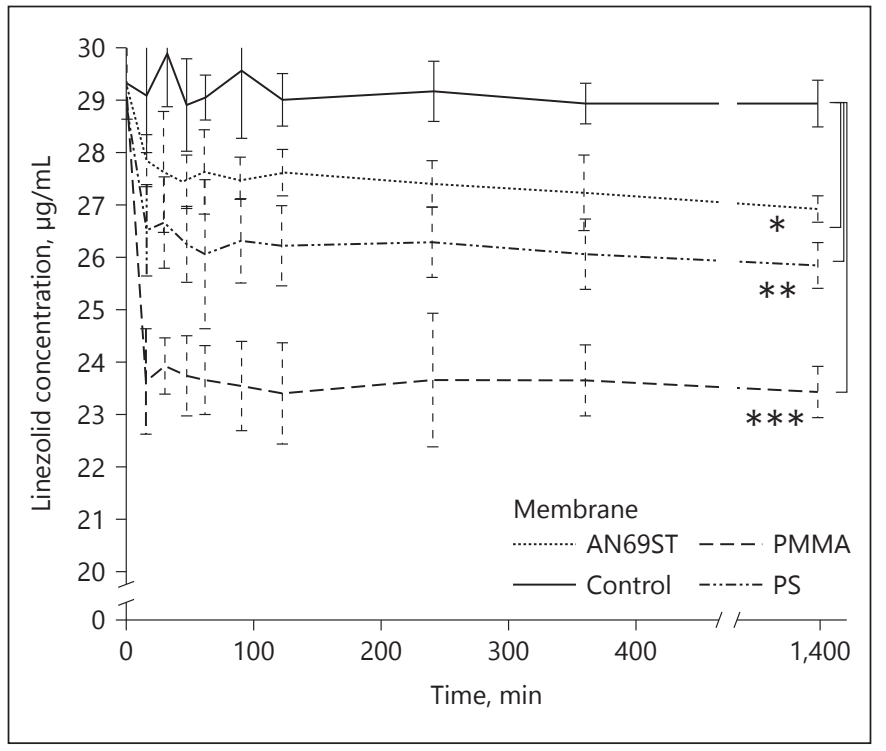

Fig. 3. Linezolid concentration from the hemofilter inlet during hemodialysis. Results are shown as mean \pm SD of 4 experiments. $* p<0.05$ versus the control group (analysis of variance). ${ }^{* *} p<$ 0.05 versus the control group (analysis of variance). ${ }^{* * *} p<0.05$ versus the control group (analysis of variance). AN69ST, polyacrylonitrile; PMMA, polymethylmethacrylate; PS, polysulfone.

spectively, with no significant differences observed at 1,440 min among the 3 types of membranes.

\section{Ra of Doripenem}

The $\mathrm{Ra}$ values for doripenem adsorption onto AN69ST, PMMA, and PS membranes at 1,440 min were $24.0 \pm 2.5,25.5 \pm 1.8$, and $27.7 \pm 2.3 \%$, respectively; these values were comparable to the $\mathrm{Ra}$ for doripenem in the control group $(23.5 \pm 2.5 \%)$, and there were no differences in Ra values among the 3 types of membrane (Table 2). 


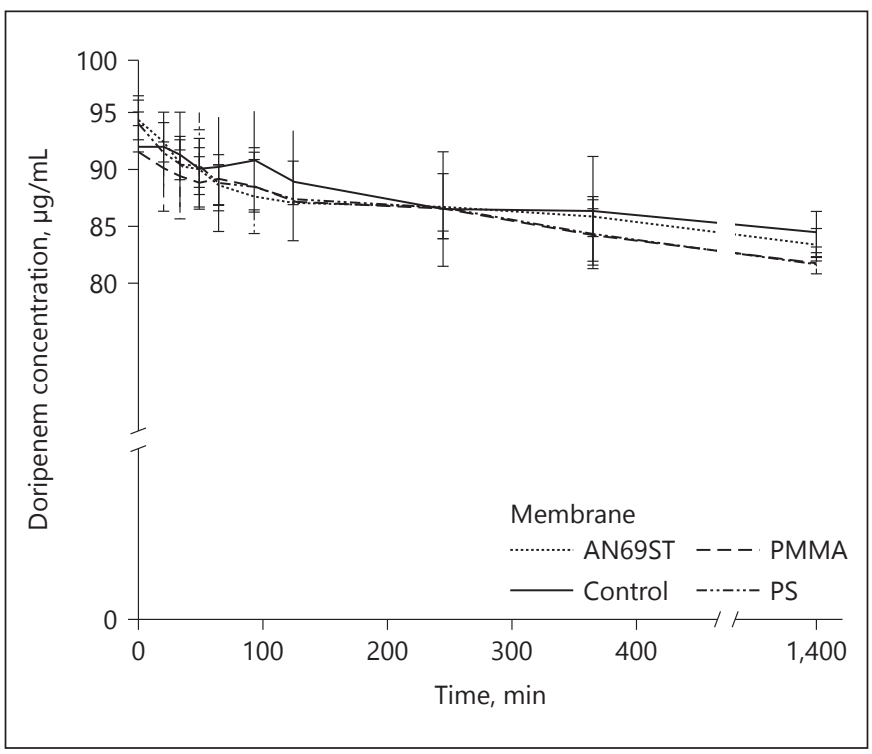

Fig. 4. Doripenem concentration from the inlet during hemodialysis. Results are shown as mean \pm SD of 4 experiments. AN69ST, polyacrylonitrile; PMMA, polymethylmethacrylate; PS, polysulfone.

\section{Discussion}

In this study, we performed in vitro experiments to evaluate the adsorption of linezolid and doripenem onto 3 different hemofilters. PMMA and AN69ST membranes, which are among the most frequently used hemofilters in RRT in Japan, have a symmetrical structure and exhibit high protein adsorption.

Other types of membranes, such as PS, polyarylethersulfone, and polyethersulfone, have an asymmetrical structure, and their separating layer is thin and located near the inner surface. In this study, we compared the antibiotic adsorption properties of PMMA, AN69ST, and PS membranes. The PMMA membrane matrix has a symmetric microporous structure that efficiently traps circulating proinflammatory cytokines used in RRT $[13,14]$. AN69ST is a copolymer of hydrophobic acrylonitrile and hydrophilic sodium methallyl sulfonate and has a symmetric hydrogel structure [15]. The surface groups derived from methallyl sulfonate monomers confer a negative charge to the membrane, allowing adsorption of cytokines via ionic bonding between the sulfonate groups and the amino groups on the cytokine surface $[16,17]$. Thus, cytokine-adsorbing hemofilters, such as PMMA and AN69ST, exhibit higher cytokine removal efficiency than does a PS membrane hemofilter.

Linezolid and Doripenem Adsorption onto Different Hemofilters
Adsorption of linezolid onto AN69ST, PMMA, and PS membranes reached an equilibrium at $15 \mathrm{~min}$ and no further adsorption was observed thereafter. In contrast, the concentration of doripenem adsorbed onto AN69ST, PMMA, and PS membranes and in the control group decreased at a constant rate from 0 to $1,440 \mathrm{~min}$.

The doripenem SC of AN69ST, PMMA, and PS membranes were $0.90 \pm 0.09,0.92 \pm 0.09$ and $0.95 \pm 0.05$, respectively. Since the protein nonbinding rate of dripenem is 0.91 , a calculated SC value of 0.91 represents the free doripenem filtered without being adsorbed on membranes [18]. Our results were similar, suggesting that doripenem was not adsorbed on AN69ST, PMMA, or PS membranes [6].

Antimicrobial drugs, such as amikacin and teicoplanin, exhibit a high Ra (60-80\%) onto PMMA and AN69 membranes in vitro $[19,20]$. However, these reports did not mention the effect of adsorption on the bioavailability of the drugs.

Linezolid is a hydrophilic antibiotic that has a low molecular weight $(337 \mathrm{Da})$, is $31 \%$ protein binding, and has a distribution volume $(\mathrm{Vd})$ of $0.79 \mathrm{~L} / \mathrm{kg}$. When linezolid is administered at a dose of $600 \mathrm{mg}$ to an adult patient with a body weight of $60 \mathrm{~kg}$, the blood concentration is $12.7 \mu \mathrm{g} / \mathrm{mL}(600 \mathrm{mg} / 0.79 \mathrm{~L} / \mathrm{kg} \times 60 \mathrm{~kg})$. The concentration of free linezolid is $8.6 \mu \mathrm{g} / \mathrm{mL}(12.7 \mu \mathrm{g} / \mathrm{mL} \times[1-0.31])$.

In our study, the concentration of linezolid adsorbed onto PMMA membrane, which showed the maximum adsorption among the 3 hemofilters, was transiently decreased by $22.0 \%$ at $15 \mathrm{~min}$ and was stable up to 1,440 min.

In this case, the amount of linezolid adsorbed onto PMMA membrane was calculated to be $1.9 \mathrm{mg}(8.6 \mu \mathrm{g} /$ $\mathrm{mL} \times 0.22 \times 1,000 \mathrm{~mL}$ ). Based on this value, the ratio of the adsorbed amount of the administered dose was estimated to be approximately $0.3 \%(1.9 / 600)$. The clearance rate of free linezolid was $16.7 \mathrm{~mL} / \mathrm{min}$ even with a nonadsorbing hemofilter, when the filtration flow rate was $1,000 \mathrm{~mL} / \mathrm{h}(16.7 \mathrm{~mL} / \mathrm{min})$; the elimination velocity of free linezolid with a non-adsorbing hemofilter was calculated to be $144 \mu \mathrm{g} / \mathrm{min}$, (i.e., $207 \mathrm{mg} / 1,440 \mathrm{~min}$ ). Thus, the adsorbed amount of linezolid $(1.9 \mathrm{mg})$ was not expected to affect treatment. Earlier reports indicated that polyacrylonitorile membranes removed $8 \%$ of the antibiotic dose, but investigators believed that a dosage change was not warranted because therapeutic serum concentrations were maintained in patients [21]. In our experiment, the effect of the Ra of $0.3 \%$ was considered to be small. Furthermore, according to a recent book on critical care nephrology by Ferrari et al. [22], membrane adsorption has 
probably a minor effect on drug removal. However, because dosing adjustment will not account for adsorption effects, drug-adsorbing membranes are usually not recommended for RRT [22].

Doripenem, a carbapenem antibiotic, often used to treat infections by Gram-negative bacteria that are resistant to most antibiotics, is hydrophilic, and it exhibits predominantly renal clearance. It has a low molecular weight $(439 \mathrm{Da})$, is only $9 \%$ protein binding, and has a $\mathrm{Vd}$ ranging from 0.2 to $0.3 \mathrm{~L} / \mathrm{kg}$.

The low stability of carbapenem drugs is widely reported in the literature $[23,24]$. In our in vitro experiments, doripenem degradation was observed in all solutions, including in the control group. After 1,440 min, the residual ratio was $70-80 \%$. Moreover, there were no differences between the amounts of doripenem adsorbed onto AN69ST, PMMA, and PS membranes and that in the control group, indicating that there was no drug adsorption by the membranes.

Blood pressure is reduced owing to a decrease in circulating plasma volume, causing a large amount of infusion to be distributed to the stroma interstitium. Linezolid and doripenem have large Vd and are thus widely distributed in the interstitium and in cells. Because drug concentration in blood is lower than that in the body, drug adsorption onto hemofilters in continuous RRT has a negligible effect on drug bioavailability $[25,26]$. In septic shock, an increase in interstitial fluid markedly increases the Vd of hydrophilic antibiotics and further decreases their blood concentration by dilution [26-28]. In the present study, we found that adsorption of linezolid and doripenem onto AN69ST, PMMA, and PS membranes did not affect the used antibiotics dose.

This study had several limitations. First, FBS was used as the test solution. Although whole blood is preferable for estimating drug concentration in vivo, a simple FBS solution is suitable for investigating drug adsorption onto a membrane. Second, linezolid and doripenem were added only once to the test solution; additional experiments in which the drugs are added repeatedly are needed to confirm whether further adsorption occurs. Third, we estimated the amount of drug adsorbed onto the PMMA membrane; however, because this value did not exceed the estimated amount, a more detailed examination is warranted. Finally, the synthetic protease inhibitor nafamostat mesylate is used as an anticoagulant in RRT in Japan. However, because protease activity can affect drug metabolism, nafamostat mesylate can increase the blood concentration of linezolid [29], which was not investigated in our study.
The results of our in vitro experiments revealed that adsorption of antimicrobial drugs onto hemofilters in RRT did not affect drug bioavailability. However, if the filtration volume was constant, the adsorption capacity of the membrane would majorly affect the drug dose. Adsorption of linezolid onto PMMA, PS, and AN69ST membranes was observed, but this was temporary and did not affect the drug dosage. Thus, various hemofilters can be used in RRT without them affecting antibiotic dosing.

\section{Acknowledgment}

None.

\section{Statement of Ethics}

The in vitro study was conducted ethically in accordance with the World Medical Association Declaration of Helsinki.

\section{Disclosure Statement}

The authors have no conflicts of interest to declare.

\section{Funding Sources}

There are no funding sources to declare.

\section{Author Contributions}

T.H.: designed the concept and created a manuscript. K. Moriyama, K. Matsumoto, Y.S., K. Morita, and O.N.: gave ethical approval and collected data. Y.K., C.Y., Y.H., J.S., and H.K.: reviewed the policies of the existing journals. T.K., Y.K., T.N., and N.K.: contributed to the writing of the final version. All the authors have approved the final version of the manuscript.

References

1 Hoste EA, Bagshaw SM, Bellomo R, Cely CM, Colman R, Cruz DN, et al. Epidemiology of acute kidney injury in critically ill patients: the multinational AKI-EPI study. Intensive Care Med. 2015 Aug;41(8):1411-23.

2 Bagshaw SM, Uchino S, Bellomo R, Morimatsu H, Morgera S, Schetz M, et al.; Beginning and Ending Supportive Therapy for the Kidney (BEST Kidney) Investigators. Septic acute kidney injury in critically ill patients: clinical characteristics and outcomes. Clin J Am Soc Nephrol. 2007 May;2(3):431-9. 
3 Cepeda JA, Whitehouse T, Cooper B, Hails J, Jones K, Kwaku F, et al. Linezolid versus teicoplanin in the treatment of Gram-positive infections in the critically ill: a randomized, double-blind, multicentre study. J Antimicrob Chemother. 2004 Feb;53(2):345-55.

4 DeRyke CA, Lodise TP Jr, Rybak MJ, McKinnon PS. Epidemiology, treatment, and outcomes of nosocomial bacteremic Staphylococcus aureus pneumonia. Chest. 2005 Sep; 128(3):1414-22.

5 Rhodes A, Evans LE, Alhazzani W, Levy MM, Antonelli M, Ferrer R, et al. Surviving sepsis campaign: international guidelines for management of sepsis and septic shock: 2016. Intensive Care Med. 2017 Mar;43(3): 304-77.

6 Vossen MG, Ehmann L, Pferschy S, MaierSalamon A, Haidinger M, Weiser C, et al. Elimination of doripenem during dialysis and pharmacokinetic evaluation of posthemodialysis dosing for patients undergoing intermittent renal repalacement therapy. Antimicrob Agents Chemother. 2018 Apr;62(5):e0243017.

7 Villa G, Di Maggio P, De Gaudio AR, Novelli A, Antoniotti R, Fiaccadori E, et al. Effects of continuous renal replacement therapy on linezolid pharmacokinetic/pharmacodynamics: a systematic review. Crit Care. 2016 Nov; 20(1):374.

8 Roberts JA, Lipman J. Pharmacokinetic issues for antibiotics in the critically ill patient. Crit Care Med. 2009 Mar;37(3):840-51.

9 Choi G, Gomersall CD, Tian Q, Joynt GM, Li AM, Lipman J. Principles of antibacterial dosing in continuous renal replacement therapy. Blood Purif. 2010;30(3):195-212.

10 Tobin CM, Sunderland J, White LO, MacGowan AP. A simple, isocratic high-performance liquid chromatography assay for linezolid in human serum. J Antimicrob Chemother. 2001 Nov;48(5):605-8.

11 Hamanoue S, Suwabe T, Ubara Y, Kikuchi K, Hazue R, Mise K, et al. Cyst infection in autosomal dominant polycystic kidney disease: penetration of meropenem into infected cysts. BMC Nephrol. 2018 Oct;19(1):272.

12 The Guidance on Nonclinical Safety Studies for the Conduct of Human Clinical Trials and
Marketing Authorization for Pharmaceuticals (M3(R2)). [MHLW/PMDA, Japan, PFSBELD Notification No. 0219-4 adopted 2010 Feb 19]. Available from: https://www.ich.org/ fileadmin/Public_Web_Site/ICH_Products/ Guidelines/Multidisciplinary/M3_R2/Step4/ M3_R2_Guideline.pdf.

13 Moriyama K, Soejima Y. Continuous hemodialfiltration using PMMA membrane: clinical efficacy and its mechanisms. Contrib Nephrol. 1999;125:222-32.

14 Nishida O, Nakamura T, Kuriyama N, Hara Y, Yumoto M, Shimomura Y, et al. Sustained high-efficiency daily diafiltration using a mediator-adsorbing membrane (SHEDD-fA) in the treatment of patients with severe sepsis. Contrib Nephrol. 2011;173:172-81.

15 Thomas M, Moriyama K, Ledebo I. AN69: evolution of the world's first high permeability membrane. Contrib Nephrol. 2011;173: 119-29.

16 Yumoto M, Nishida O, Moriyama K, Shimomura Y, Nakamura T, Kuriyama N, et al. In vitro evaluation of high mobility group box 1 protein removal with various membranes for continuous hemofiltration. Ther Apher Dial. 2011 Aug;15(4):385-93.

17 Shiga H, Hirasawa H, Nishida O, Oda S, Nakamura M, Mashiko K, et al. Continuous hemodiafiltration with a cytokine-adsorbing hemofilter in patients with septic shock: a preliminary report. Blood Purif. 2014;38(3-4): 211-8.

18 Böhler J, Donauer J, Keller F. Pharmacokinetic principles during continuous renal replacement therapy: drugs and dosage. Kidney Int Suppl. 1999 Nov;56(suppl 72):S24-8.

19 Tian Q, Gomersall CD, Ip M, Tan PE, Joynt GM, Choi GY. Adsorption of amikacin, a significant mechanism of elimination by hemofiltration. Antimicrob Agents Chemother. 2008 Mar;52(3):1009-13.

20 Shiraishi Y, Okajima M, Sai Y, Miyamoto K, Inaba $\mathrm{H}$. Elimination of teicoplanin by adsorption to the filter membrane during haemodiafiltration: screening experiments for linezolid, teicoplanin and vancomycin followed by in vitro haemodiafiltration models for teicoplanin. Anaesth Intensive Care. 2012 May;40(3):442-9.
21 Mauro LS, Peloquim CA, Schmude K, Assaly R, Malhotra D. Clearance of Linezolid via Continuous Venovenous Hemodiafiltration. Am J Kidney Dis. 2006 Jun;47(6):e836.

22 Ferrari F, Sartori M, Milla P. Antibiotic adjustment in CRRT. In: Ronco C, Bellomo R, Kellum JA, Ricci Z, editors. Critical Care Nephrology. 3rd ed. Philadelphia: Elsevier; 2017. pp. 1051-67.

23 Roth T. Fiedler, Mihai S, Parsch H. Determination of meropenem levels in human serum by high-performance liquid chromatography with ultraviolet detection. Biomed Chromatogr. 2017 May;31(5).

24 Dailly E, Bouquié R, Deslandes G, Jolliet P, Le Floch R. A liquid chromatography assay for a quantification of doripenem, ertapenem, imipenem, meropenem concentrations in human plasma: application to a clinical pharmacokinetic study. J Chromatogr B Analyt Technol Biomed Life Sci. 2011 May;879(15-16): 1137-42.

25 Trotman RL, Williamson JC, Shoemaker DM, Salzer WL. Antibiotic dosing in critically ill adult patients receiving continuous renal replacement therapy. Clin Infect Dis. 2005 Oct; 41(8):1159-66.

26 Gonçalves-Pereira J, Póvoa P. Antibiotics in critically ill patients: a systematic review of the pharmacokinetics of $\beta$-lactams. Crit Care. 2011;15(5):R206.

27 Katip W, Jaruratanasirikul S, Pattharachayakul S, Wongpoowarak W, Jitsurong A, Lucksiri A. The pharmacokinetics of vancomycin during the initial loading dose in patients with septic shock. Infect Drug Resist. 2016 Nov;9: 253-60.

28 Seyler L, Cotton F, Taccone FS, De Backer D, Macours P, Vincent JL, et al. Recommended $\beta$-lactam regimens are inadequate in septic patients treated with continuous renal replacement therapy. Crit Care. 2011;15(3): R137.

29 Nakamura Y, Hara S, Hatomoto H, Yamasaki S, Nakano T, Miyazaki M, et al. Adsorption of Nafamostat Mesilate on AN69ST Membranes: A Single-Center Retrospective and In Vitro Study. Ther Apher Dial. 2017 Dec;21(6):6207.
Linezolid and Doripenem Adsorption onto Different Hemofilters
Blood Purif 2020;49:295-301 